\title{
Yarn Crimp Ratio in Woven Fabrics Theory and Practice
}

\author{
By: Hamdy A. A. Ebraheem \\ Lecturer in Textile Eng. Dept. Mansoura University \\ نسبة تشريب الفيوط فو الأقمشة المفهوجة \\ نظويا ومعليا
}

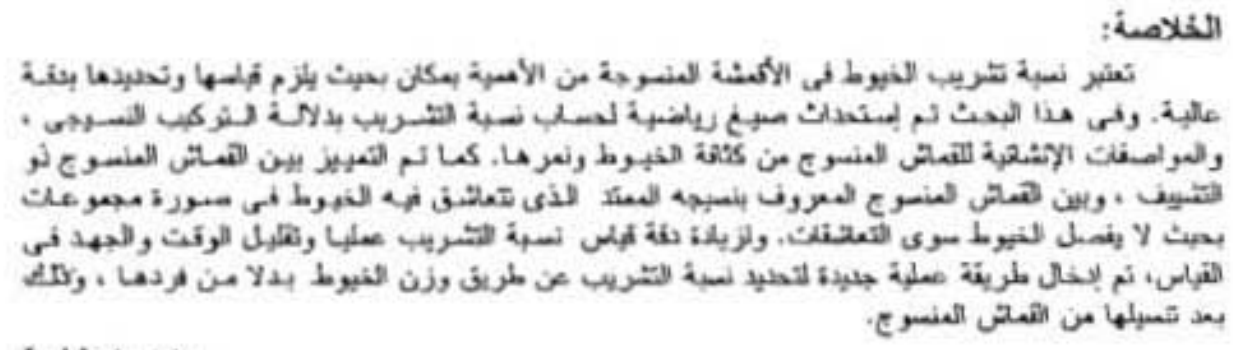

\section{Abstract:}

Because of the importance of accuracy in measuring and estumating yam crimp ratio in woven fabrics, non classical methods were searched for. In this paper mathernatical formulac were derived to express yarn crimp ratio in terms of weave structure, yam spacing, and yarn diameter. It is descriminated between floated weaves and extended weaves. In floated weaves yam spacing is constant and equal to yarn spacing at the point of intersection. In extended weaves, yarns are separated only at points of intersection. To increase accuracy and safe effort and time consuativi in measuring yarn crimp ratio, a new experimental method is introduced. In this method yarn crimp ratio is determined by weighing crimped yarns instead of decrimping thern.

\section{Introduction:}

There have been many simpie empirical inodels to relate fabric parameters. These models need more modifications by using the eiectronical computing systems [1]. Simple mathematical models had been improved and modified in the from of dimensioniess relations [2]. The weave structure can be expressed in terms of average Boat or float ratio. It was found that the mean value of warp tension decreases by increasing the float ratio [3].

Fabric abrasion resistance is affected by yarn crimp ratio because crowns formed as yarn bends round a transverse thread will protrude from the fabric surface and meet the destructive abrasive agent first. The largest amount of fabric shrinkage is that represented by increase of crimp. Control of crimp percentage is necessary when a fabric is designed to give a desired degree of extensibility and when crimp balance between warp and weft is required after finishing processes. Knowledge of crimp value is useful in calculating fabric cost and yam requirement [4]

It is clear that yam crimp ratio plays important parts in fabric analysis, fabric research and design, process control, and economics of fabric production 
III. Nomenclature:

$A_{i}$ The number of weft yarns over which the warp end passes in the $i^{\text {th }}$ fraction of warp weave repeat.

$\mathrm{B}_{\mathrm{i}}$ The number of weft yams under which the warp end passes in the $i^{\text {th }}$ fraction of warp weave repear.

$C_{1}$ Warp crimp ratio in the woven fabric.

$\mathrm{C}_{2}$ Weft crimp ratio in the woven farbic.

$\left(C_{1}\right)_{2 / 1}$ Warp crimp ratio in plain - woven fabric

$\left(C_{2}\right)_{141}$ Weft crimp ratio in plain-woven fabric.

$d_{t}$ Diameter of warp end

(cm).

$d_{2}$ Diameter of weft yam

$F_{1}$ Average float of warp end.

$\mathrm{F}_{2} \quad$ Average float of weft yam.

$\mathrm{G}_{\mathrm{i}}$ The number of warp ends over which the weft yaun passes in the $\mathrm{i}^{\text {th }}$ fraction of weft weave repeat.

$\mathrm{H}_{i}$ The number of warp ends under which the weft yarn passes in the $i^{\text {th }}$ fraction of wett weave repeat

$\mathrm{K}_{\text {I }}$ Warp cover ratio.

$\mathrm{K}_{2}$ Weft cover ratio.

Li Warp modular length

$\mathrm{L}_{2}$ WeAt modular length

(cm).

L Lenght of weave repeat

(cm).

(cm)

$\mathrm{m}$ Number of fractions in repeat of weft interlacing.

$n$ Number of fractions in repeat of warp interiacing.

$n_{1}$ Average number of ends $/ \mathrm{cm}$.

$\mathrm{n}_{2}$ Average number of picks $/ \mathrm{cm}$.

$\mathrm{N}$ Number of yams.

$P_{1}$ Distance between two neighbouring warp ends at a weft intersection ( $\mathrm{cm}$ ).

$\mathrm{P}_{2} \quad$ Distance between two neighbouring weft yarns at a warp intersection $(\mathrm{cm})$.

W Width of weave repeat

$\theta_{1}$ Warp weave angle

$\theta_{2}$ Weft weave angle

\section{rV. Mathematical Derivation:}

Figures 1 and 2 show an example of floated weaves and extended weaves (3/1) respectively,

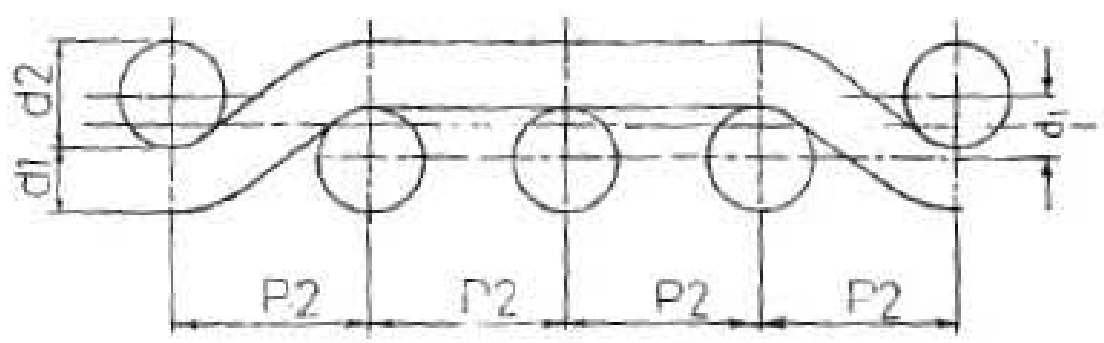

Fig (1) A cross - section floated weave $3 / 1$ 


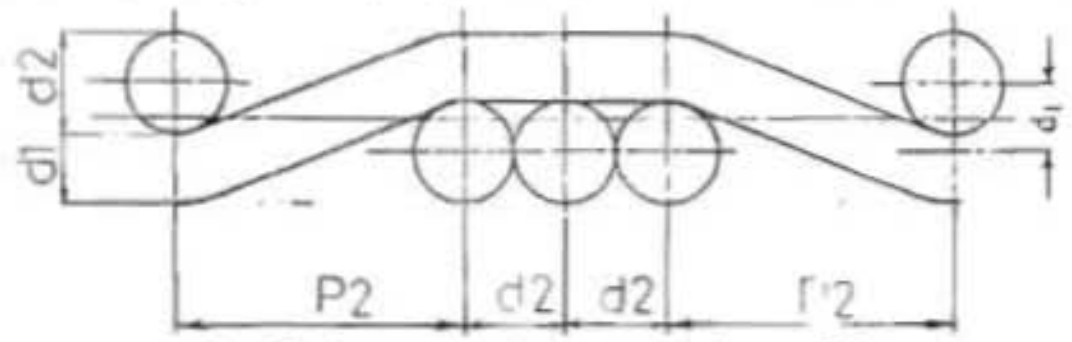

Fig (2): A cross - section in extended weave 3/1

\section{IV.I. Fabrics of Floated Weaves:}

Let warp interiacing repeat be $\frac{A_{1} A_{2} A_{3}}{B_{3} B_{2} B_{3}}-\frac{A_{2}}{B_{n}}$ and weft interlacting repeat be $\frac{G_{1} G_{2} G_{2} \ldots G_{2}}{H_{1} H_{2} H_{3} \ldots \ldots . H_{3}}$

Then Number of warp interlacings $/$ repeat $=2 \mathrm{n}$

$$
\begin{array}{ll}
\text { Number of picks/repeat } & -\sum_{i=1}^{\infty} A_{1}+\sum_{i=1}^{\infty} B_{i} \\
\text { Warp length / repeat } & -2 n L_{1}+P_{2}\left(\sum_{i=1}^{\infty} A_{i}+\sum_{i=1}^{\infty} B_{1}-2 n\right) \\
\text { Length of repeat } & =P_{2}\left(\sum_{i=1}^{\infty} A_{i}+\sum_{i=1}^{\infty} B_{i}\right)
\end{array}
$$

$\therefore$ Warp Crimp Ratio

$$
\begin{aligned}
& C_{1}=\frac{2 n\left(L_{1}-P_{2}\right)}{P_{1}\left(\sum A_{i}+\sum B_{1}\right)}=\frac{2 n}{\sum A_{1}+\sum B_{3}}\left(\frac{L_{1}-P_{2}}{P_{3}}\right) \\
& C_{1}=\frac{2 n}{\sum A_{1}+\sum B_{1}} \cdot\left(C_{1}\right)_{m}
\end{aligned}
$$

$\left(C_{1}\right)_{n n}$ is warp crimp ratio in plain woven fabric. Similarly

$$
c_{2}=\frac{2 m}{\sum G_{1}+\sum H_{1}} \cdot\left(c_{2}\right)_{21}
$$

$\left(C_{2}\right)_{n}$ is weft crimp ratio in plain woven fabric.

$$
C_{1}=\frac{\left(C_{1}\right)_{\text {inc }}}{F_{1}}
$$

and

$$
\mathrm{C}_{1}=\frac{\left(\mathrm{C}_{2}\right)_{1+1}}{\mathrm{~F}_{2}}
$$

$F_{1}$ and $F_{2}$ are average float of warp and weft, respectiveiy.

From a previous study [5]

$$
\left(C_{1}\right)_{n}=\operatorname{Sec} \theta_{1}-\frac{2 d}{P_{2}} \tan \theta_{1}+\frac{2 d}{P_{2}} \theta_{1}-1
$$

when $\theta_{1}<\frac{\pi}{2}$ 


$$
\left(C_{2}\right)_{M}=\operatorname{Sec} \theta_{2}-\frac{2 d}{P_{1}} \tan \theta_{2}+\frac{2 d}{P_{1}} \theta_{2}-
$$

when $\theta_{2}<\frac{\pi}{2}$

When $\theta_{1}=\frac{\pi}{2}, \theta_{2}=0, C_{1}=\frac{\pi d}{P_{2}}-1$, and $C_{2}=0$

When $\theta_{2}=\frac{\pi}{2}, \theta_{1}=0, C_{2}=\frac{\pi d}{P_{1}}-1$, and $C_{1}=0$

$$
\operatorname{Sin} \theta_{1}=\frac{2 d P_{2}-d_{1} \sqrt{P_{2}^{2}-d_{2}\left(2 d+d_{1}\right)}}{P_{1}^{2}+d_{1}^{2}}
$$

$$
\begin{aligned}
& \operatorname{Sin} \theta_{2}=\frac{2 d P_{1}-d_{2} \sqrt{P_{1}^{2}-d_{1}\left(2 d+d_{2}\right)}}{P_{3}^{2}+d_{2}^{2}} \\
& d_{1}+d_{2}=2 d
\end{aligned}
$$

$d_{1}$ and $d_{2}$ are warp yarn and weft yarn diameters, and $P_{1}$ and $P_{2}$ are yarn spacing for warp and weft, respectuvely.

Yam crimp ratio can also be expressed as follows:

$$
\begin{aligned}
& C_{1}=\left(C_{1}\right)_{21} \cdot \frac{\text { Warp int erlacings / repeat }}{\text { Picks / repeat }} \\
& C_{2}=\left(C_{2}\right)_{1 n} \cdot \frac{\text { Weft int erlacings / repeat }}{\text { Ends } / \text { repeat }}
\end{aligned}
$$

$\left(C_{1}\right)_{1 / 1}$ and $\left(C_{2}\right)_{1 n}$ are functions of

$$
\begin{array}{ll}
\text { - warp diameter } d_{1} & \text { - weft diameter } d_{2} \\
\text { - warp spacing } P_{1} & \text { - weft spacing } P_{2}
\end{array}
$$

The contribution of weave structure in the value of $\mathrm{C}_{1}$ and $\mathrm{C}_{2}$ is represented in warp interlacings / repeat as a ratio of picks / repeat and weft interlacings/ repeat as a ratio of ends / repeat (equations 10 and 11). In other words the contribution of weave structure is represented in warp arerage float and weft average float (equations 3 and 4).

Example:

$$
\text { Let } \begin{array}{ll}
d_{1}=0.02 \mathrm{~cm} & d_{2}=0.03 \mathrm{~cm} \\
P_{1}=0.05 \mathrm{~cm} & P_{2}=0.07 \mathrm{~cm}
\end{array}
$$

$\therefore$ Weave angles can be calculated from equations 7 and 8 .

$$
\theta_{1}=27.43^{\circ} \quad \theta_{2}=28.07^{\circ}
$$

Crimp ratios can be calculated from equations 5 and 6 .

$$
\left(C_{1}\right)_{y+1}=0.0979 \quad\left(C_{2}\right)_{m}=0.08995
$$

Table (1) shows the effect of weave structure (average float) on yam crimp ratios: 
Table (1): Average float of different weaves and the corresponding values of crimp ratio (d) $=0.02 \mathrm{~cm}, d_{2}=0.03 \mathrm{~cm}, P_{1}=0.05 \mathrm{~cm}$, and $P_{2}=0.07 \mathrm{~cm}$ ).

\begin{tabular}{|c|c|c|c|}
\hline Yarn interlacing Repeat & Average Float & $\mathrm{C}_{1}$ & $\mathrm{C}_{2}$ \\
\hline$\vdots$ & 1 & 0.0979 & 0.08995 \\
$\frac{1}{3}$ & 1.5 & 0.0653 & 0.05997 \\
$\frac{13}{23,}$ & 2.5 & 0.0489 & 0.04479 \\
$\frac{2}{4}$ & 3 & 0.0392 & 0.03598 \\
\hline
\end{tabular}

\section{IV.2. Fabrics of Extended Weaves:}

In the above-mentioned analysis yam spacing $P$ is taken constant i.e yams are uniformly spread along and across the woven favric. In extended weaves every group of yarns interlace alike and behave as one yarn i.e they run side by side without gaps except at points of intersection where yarn set is divided into groups. Basket weave, warp rib and weft rib are popular examples of such weaves. In this case yan spacing is not constant.

Length of weave repeat $L=2 n P_{2}+\left(\sum A_{i}+\sum B_{1}-2 n\right) d_{2}$

Warp length $/$ repeat $=2 n L_{1}+\left(\sum A_{1}+\sum B_{i}-2 n\right) d_{2}$

$\therefore$ Warp Crimp Ratio $C_{1}=\frac{2 n\left(L_{i}-P_{1}\right)}{2 n P_{2}+\left(\sum A_{1}+\sum B_{1}-2 n\right) d_{2}}$

$$
C_{1}=\left(\frac{L_{1}-P_{2}}{P_{2}}\right) /\left\{1+\frac{\left(\sum A_{1}+\sum B_{1}-2 n\right) d_{2}}{2 n P_{2}}\right\}
$$

From (12)

$$
\begin{aligned}
P_{2} & =\frac{L-\left(\sum A_{1}+\sum B_{i}-2 n\right) d_{2}}{2 n} \\
P_{2} & =\frac{L}{2 n}-\left(F_{1}-1\right) d_{2} \\
& =\frac{F_{1}}{n_{2}}-\left(F_{1}-1\right) d_{2}
\end{aligned}
$$

$\mathrm{m}_{2}$ is overall weft denisty (picks/cm).

Similary

Weft Crimp Ratio

$$
C_{2}=\left(\frac{L_{2}-P_{1}}{P_{1}}\right) /\left\{1+\frac{\left(\sum G_{1}+\sum H_{1}-2 m\right) d_{1}}{2 m P_{1}}\right\}
$$

If width of repeat is $w$

$$
P_{1}=\frac{w-\left(\sum G_{i}+\sum H_{i}-2 m\right) d_{i}}{2 m}
$$




$$
\begin{aligned}
& P_{1}=\frac{w}{2 m}-\left(F_{2}-1\right) d_{1} \\
& P_{1}=\frac{F_{2}}{n_{1}}-\left(F_{2}-1\right) d_{1}
\end{aligned}
$$

$\mathrm{n}_{\mathrm{l}}$ is overalt warp density (ends / $\mathrm{cm}$ ).

From (14) and (17)

$$
\mathrm{C}_{1}=\frac{2 \mathrm{nP}_{2}}{\mathrm{~L}}\left(\mathrm{C}_{1}\right)_{n}
$$

and

$$
\mathrm{C}_{2}=\frac{2 \mathrm{mP}}{\mathrm{w}}\left(\mathrm{C}_{2}\right)_{11}
$$

It may be more appropriate to count the number of weft threads / unit length of the fabric than to measure the lenght of weave repeat. The unit lenght must be as great as possible in order to obtain as many complete weave repeats as possible. After counting the number of picks / unit lenght, the overall number of picks $/ \mathrm{cm}\left(\mathrm{n}_{2}\right)$ can be computed.

$$
\mathrm{L}=\frac{\sum \mathrm{A}_{\mathrm{i}}+\sum \mathrm{B}_{\mathrm{i}}}{\mathrm{n}_{2}}
$$

Similarly

$$
W=\frac{\sum G_{i}+\sum H_{i}}{n_{t}}
$$

It can be derived that

$$
\begin{aligned}
& C_{1}=\left[1-\frac{n_{2} d_{2}\left(\sum A_{1}+\sum B_{1}-2 n\right)}{\sum A_{i}+\sum B_{1}}\right]\left(C_{1}\right)_{11} \\
& C_{1}=\left\{1-\frac{K_{2}\left(F_{1}-1\right)}{F_{1}}\right\}\left(C_{1}\right)_{11}
\end{aligned}
$$

and Similarly

$$
\text { and } \begin{aligned}
C_{2} & =\left\{1-\frac{K_{1}\left(F_{2}-1\right)}{F_{2}}\right\}\left(C_{2}\right)_{1,1} \\
K_{1} & =n_{1} d_{1} \\
K_{2} & =n_{2} d_{2}
\end{aligned}
$$

\section{Procedure of Calculations:}

\section{V.1. Fabrics of Floated Weaves:}

Given: Weave structure, yarn diameters (warp and weft), and yarn spacings (warp and weft).

\section{Calculations:}

- From weave structure, yarn arerage float is estimated (warp and weft).

- From yarn diameters and yarn spacings, weave angles and yarn crimp ratios of plain weave can be caiculated.

- From yam crimp ratio of plain weave and yarn average float, yarn crimp ratio of the considered weave structure is estimated 


\section{V.2. Fabrics of Extended Weaves:}

Given: Weave structure, yam diameters (warp and weft) and average yarn densities (warp and weft).

\section{Calculations:}

- From weave structure, yarn average float is estimated (warp and weft)

- From yam dianieter and yam density, yarn cover ratio can be estimated (warp and weft).

- From yarn average float, yam dianeters, and yam densities, yam spacing for plain weave (yam spacing at points of intersection) can be estimated.

- Fram yarn spacing at points of intersection and yarn diameters, yarn crimp ratis for plain weave can be estimated.

- From yarn cover ratios, yarn average floats, and yarn crimp ratios for piain weave, yarn crimp ratios for the considered weave structure can be estimated

Figures 3 and 4 show a descrimination between floated and extended weaves with respect to crimp ratio.

\section{A New Method for Measuring Yarn Crimp Ratio;}

The usual procedure followed to estimate yarn crimp ratio [5] is to measure:

1. The distance bet, two points on the yarn in the plane of the fabric $\left(\mathrm{L}_{\mathcal{C}}\right)$

2. The distance between the previously considered two points when the yarn is straightened i.e. decrimped $\left(\mathrm{L}_{s}\right)$

Then yarn crimp ratio is estimated as follows.

$$
C=\frac{L_{1}-L_{4}}{L_{c}}
$$

Determining the lenght $L_{s}$ needs straightening the crimped yam by applying a certain tensile load (decrimping load). The decrimping load is that sufficient to straighten the yam without causing any elongation. This decrimping load is a function of [4] yam material, yam structure, and yam count ie. yam properties. It is clear that the value of the decrimping load is not only difficult to be specified but also a critical value. This means that a load less than the proper decrimping load results in a value of crimp ratio less than the real value and a load more than the proper decrimping load results in a value of crimp ratio more than the real value. There is no doubt that the previous formula (equation 27) of calculating yarn crimp ratio is right but the problem lies in determining the value of $L_{3}$, This problem can be overcome by the following procedure:

Muitiplying the numerator and denominator in (27) by yam cross sectional area and yarn density (weight / unit volume), then

$$
\mathrm{C}=\frac{\mathrm{w}_{1}-\mathrm{w}_{\mathrm{e}}}{\mathrm{w}_{\mathrm{s}}}
$$

$\mathrm{W}_{\mathrm{S}}$ is the weight of the unravelled yam, $\mathrm{W}_{\mathrm{c}}$ is the weight of a portion of the yam of lengh equal to the distance between the ends of the unravelled yam in the plane of the fabric. This formula is based on the imporvement of yam regulanty as it is suitable for only regular yams. $\mathrm{W}_{\mathrm{c}}$ can be calculated from yarn count and $\mathrm{L}_{\mathrm{c}}$. If $\mathrm{L}_{\mathrm{c}}$ is in meters and yam count is in $\mathrm{N}_{m}$ (metric count), then

$$
\mathrm{W}_{e}=\frac{\mathrm{L}_{\mathrm{e}}}{\mathrm{N}_{\mathrm{m}}}
$$

$\mathrm{W}_{\mathrm{c}}$ is in $\mathrm{gm}$ 


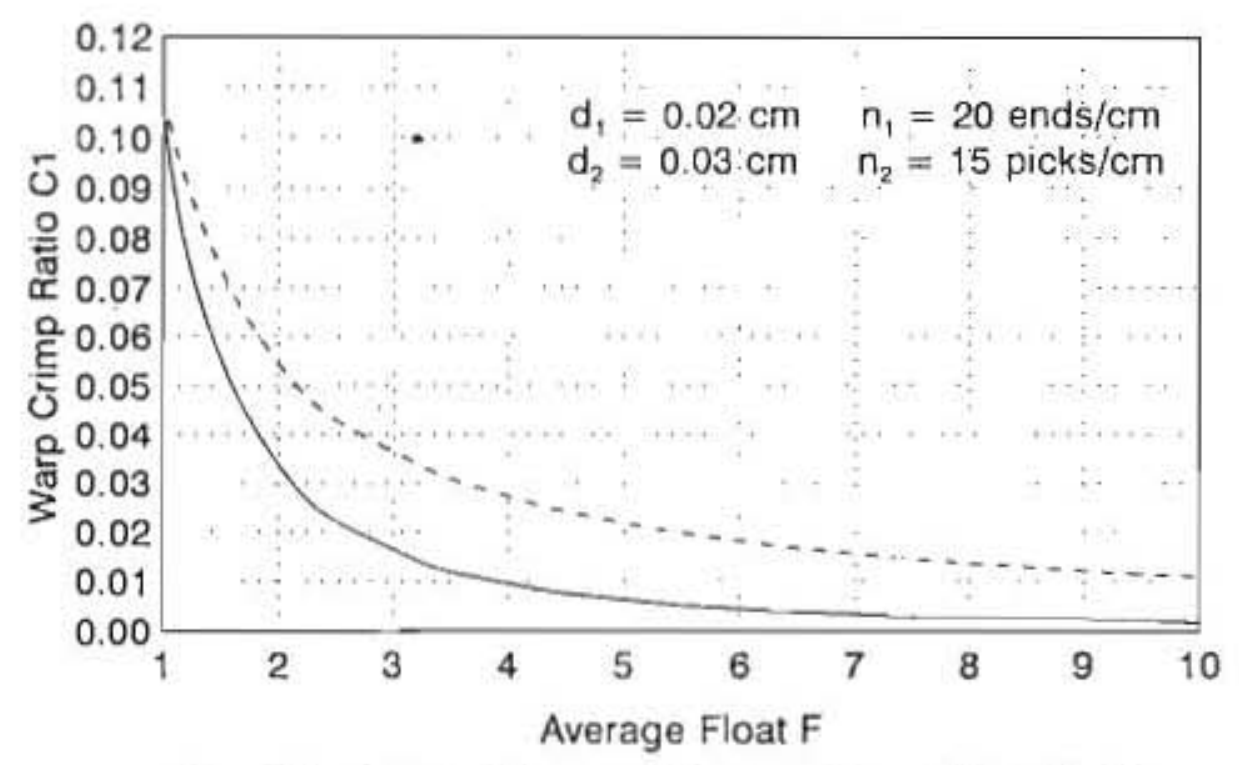

Fig. (3) : Effect of Aerage Float on Warp Crimp Ratio

- Floated Weave - Extended Weave

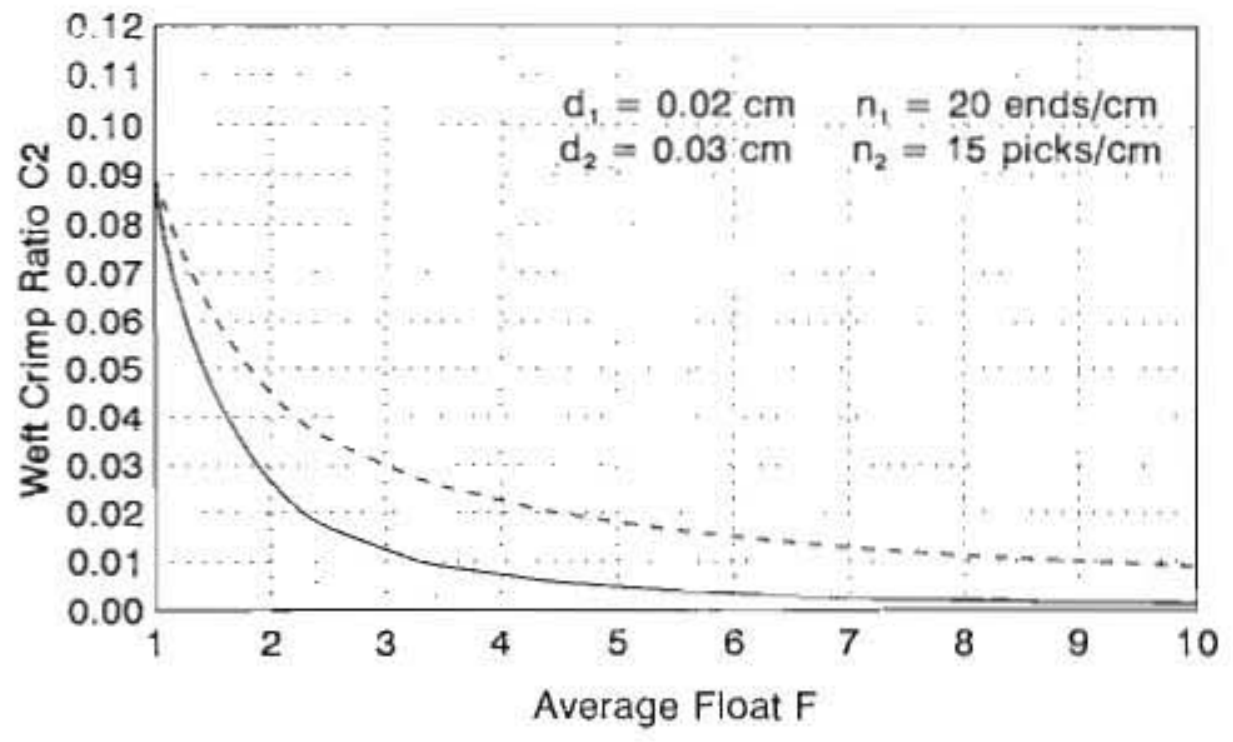

Fig. (4) : Effect of Aerage Float on Weft Crimp Ratio

- Floated Weave - Extended Weave 


$$
\begin{aligned}
& C=\frac{W_{c}-L_{c} / N_{m}}{L_{s} / N_{m}} \\
& C=\frac{W_{c} \cdot N_{m}}{L_{s}}-1
\end{aligned}
$$

If $\mathrm{W}_{\mathrm{S}}$ is the weight of one unravelled yarn, $\mathrm{C}$ will be the corresponding crimp ratio. If $\mathrm{W}_{\mathrm{s}}$ is the mean weight of a number of unravelled yams of the same $\mathrm{L}_{c}$, then $\mathrm{C}$ will be the average yarn crimp ratio. It can be concluded that if $\mathrm{N}$ yams have a weight $\mathrm{W}$, the $\mathrm{W}_{\mathrm{s}}$ will be equal to the total weight divided by the number of yarns i.e. $W_{1}=\frac{W}{N}$

$$
\mathrm{C}=\frac{\mathrm{W} \cdot \mathrm{N}_{\mathrm{B}}}{\mathrm{N} \cdot \mathrm{L}}-
$$

It is worth saying that this relation is another form of the formula used to caiculate weight of $\mathrm{N}$ crimped yams of the same crimped lenght $\mathrm{L}_{c}$, yarn erimp ratio $\mathrm{C}$, and yarn count $\mathrm{N}_{\mathrm{m}}$. The last formula can be rewrittm as follows:

$$
C=\frac{N_{m}}{\left(N_{m}\right)_{e}}-1
$$

$\left(N_{m}\right)_{s}$ is the metric count of the crimped yarn.

\section{Procedure of Crimp Ratio Testing:}

1- Prepare a rectangular or square sample of fabric of adequate dimensions.

2. Measure lenght and width of the sample to obtain the yam crimped lengh $\mathrm{L}_{c}$ of each of warp and weft.

3. Unravel a number $\mathrm{N}$ of yarns (e.g warp) and weigh them to obtain the weight $\mathrm{W}$ of $\mathrm{N}$ yarns

4. Estimate the yarn count $\mathrm{N}_{\mathrm{m}}$ of each of warp and weft if it is unknown.

5. Substitute in formula (31) to give the average crimp ratio of $\mathrm{N}$ yarns.

\section{Verification:}

Yarn crimp ratio in different samples of woven fabric is estimated by 4 different methods: 3 expenmental methods besides the theoretical method considered in this paper. The 3 experimental methods are:

1- Decrimping method.

2. Weighing method and using nominal counts.

3. Weighing method and using estimated values of counts (counts are estimated by decrimping and weighing)

Table (2) shows the results of these 4 methods. It is clear that although styles 1 and 4 have the same constructional details, they differ in values of crimp ratios estimated by the 3 experimental methods. It is also clear that the first and third methods give the same results. In square fabrics where warp and weft specifications are the same (styles $1,2,4,5$ and 8 ) the experimental values of crimp ratio are not the same for warp and weft.

To determine the most suitabic method for crimp ratio estimation, fabric weight $\left(\mathrm{g} / \mathrm{m}^{2}\right)$ is measured and also estimated using crimp ratios obtained from the different 4 methods. This is shown in Table (3). It is clear from the table that the decrimping 
method and the weighting method (estimated counts) of crimp estimation give nears: the same vaitue of estimated fabric weight. It is also clear that the weighing methoc (nominal counts) give fabric weight which is the nearest to the measured value in 4 styles and the theoretical method is the nearest in 3 styles whereas the othet 2 methods are the nearest in 1 style

Table (3): Fabric Weight $\left(\mathrm{g} / \mathrm{m}^{2}\right)$ Measured and Estimated Using Crimp Ratios Obtained by the 4 Different Methods of Crimp Ratio Estimation

\begin{tabular}{|c|c|c|c|c|c|}
\hline \multirow[b]{3}{*}{ Style } & \multicolumn{5}{|c|}{ Fabric Weight $\left(g / \mathrm{a}^{2}\right)$} \\
\hline & \multirow{2}{*}{$\begin{array}{l}\text { Measured } \\
\text { Value }\end{array}$} & \multicolumn{4}{|c|}{ Estimated Valuc } \\
\hline & & $\begin{array}{l}\text { Decrimping } \\
\text { Method }\end{array}$ & $\begin{array}{l}\text { Weighing Method } \\
\text { (nominal counts) }\end{array}$ & $\begin{array}{l}\text { Weighing Method } \\
\text { (estimated counts) }\end{array}$ & $\begin{array}{l}\text { Theoretical } \\
\text { Method }\end{array}$ \\
\hline 1 & 166.67 & 151.71 & 16170 & 151.71 & 15980 \\
\hline 2 & 218.18 & 20540 & 21127 & 205.40 & 209.90 \\
\hline 3 & 200.00 & 177.49 & 186.40 & 177.78 & 172.85 \\
\hline 4 & 168.75 & 156.95 & 157.30 & 156.95 & 159.80 \\
\hline 5 & 206,00 & 195.10 & 18199 & 19500 & 20790 \\
\hline 6 & 168,57 & 161.07 & 166.69 & 16110 & 146.68 \\
\hline 7 & 180.00 & 16870 & 16360 & 16929 & 161,00 \\
\hline 8 & 240.00 & 22720 & 246.30 & 227.00 & 243.56 \\
\hline
\end{tabular}

\section{Conclusion:}

Both the weighing method (nominal counts) and the theoretical method can be preferabiy used in estimafing yam crimp ratio in woven fabrics. Weighing methods compnses unravelling yams from fabric, weighing them and then estimating yam nominal count (as in specifications of fabric), number of unravelled yarns, and yam crimped length (the new method of crimp estimation). The theoretical method needs measuring yam densities (or yarn spacing), and yarn diameter (from yarn count), and determining yam average float (from weave structure repeat). Then substituting in mathematical formulae derived in this paper gives the values of yarn crimp ratios.

\section{References:}

[1] Peirce, F. T. The Geometry of Cloth Structure, J T. I, Vol 28. T45-T112. 1937.

[2] El-Deeb, A. and Shaheen, A. Theoretical and Experimental Suadies for Thread Fioating in the Fabric, Mansoura Engineering Journal, Vol. 15, No. 2, December 1990.

[3] Weinsdoerfer, H. Garnheabspnuchung beim Weben von Fasergarnen, Textil Praxis International, $8+9,1988$.

[4] I. E. Booth, Prnciples of Textile Testing, Newness-Butterworths, 1968, 265271 .

[5] H. A. A. Ebraheem, Geumetry of Plain Woven Fabric Made fron Flexible Yarns, Mansoura Engineering Journal, Vol. 20, No.2, June 1995. 


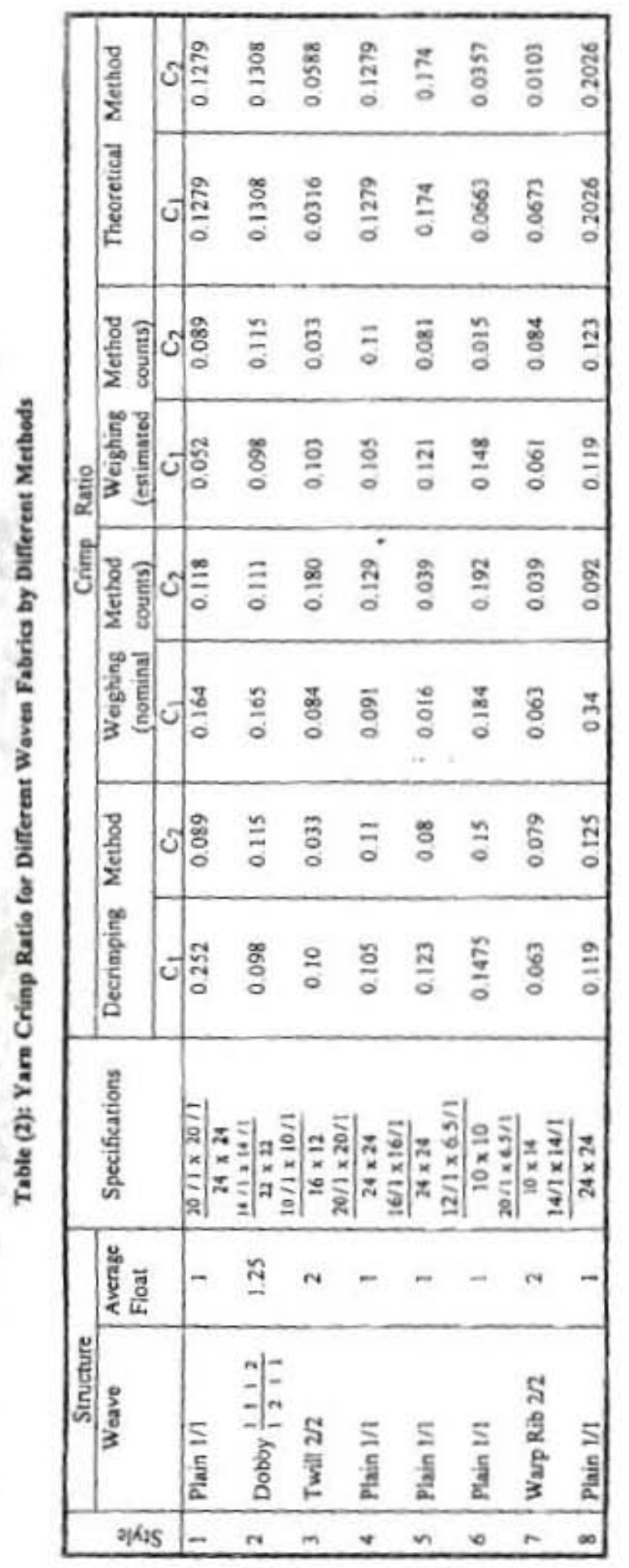

